\title{
Program Fisioterapi Komprehensif Pada Penyakit Paru Obstuksi Kronis (PPOK) Eksaserbasi Akut
}

\author{
Rizky Putri Bintari ${ }^{1}$, Farid Rahman ${ }^{\otimes 1}$ \\ ${ }^{1}$ Program Studi Fisioterapi, Fakultas Ilmu Kesehatan, Universitas Muhammadiyah Surakarta \\ Jl. A. Yani Tromol Pos I Pabelan Kartasura Telp. (0271) 717417 Fax. (0271) 715448 Surakarta 57162 \\ 凶email: Fr280@ums.ac.id \\ Tanggal Submisi: 3 Maret 2020 ; Tanggal Penerimaan: 7 Juli 2020
}

\begin{abstract}
ABSTRAK
PPOK merupakan penyakit umum yang dapat dicegah dan diobati, ditandai dengan gejala pernapasan persisten dan keterbatasan aliran udara yang disebabkan oleh saluran napas dan / atau kelainan alveolar yang biasanya disebabkan oleh paparan yang signifikan terhadap partikel atau gas berbahaya yang menyebabkan berbagai gangguan diantaranya sesak napas, perubahan pola pernapasan, spasme otot, dan penurunan ekspansi thoraks. Untuk mengetahui pelaksanaan fisioterapi dalam mengurangi derajat sesak napas, normalisasi pola pernapasan, rileksasi otot, dan meningkatkan ekspansi thoraks dengan modalitas infra red, sustained maximal inspiration, chest physiotherapy, dan latihan batuk efektif. Setelah dilakukan terapi selama tiga kali diperoleh hasil penilai derajat sesak napas T0: 6 menjadi T3: 4, penurunan nyeri pada nyeri tekan T0: 4 menjadi T3: 2, nyeri gerak T0: 2 menjadi T3: 1, perubahan pola pernapasan T0: prolonged expiration menjadi T3: prolonged expiration, peningkatan ekspansi thoraks pada ICS T0: $1 \mathrm{~cm}$ menjadi T3: $1,5 \mathrm{~cm}$, pada processus xiphoideus T0: $1 \mathrm{~cm}$ menjadi T3: $1,5 \mathrm{~cm}$ dan peningkatan aktivitas T0: 70 menjadi T3: 80. Infra red, sustained maximal inspiration, chest physiotherapy, dan latihan batuk efektif dapat mengatasi gangguan yang ada pada kasus penyakit paru obstruktif kronik eksaserbasi akut.
\end{abstract}

Kata Kunci: Penyakit paru obstruktif kronik eksaserbasi akut, infra red, sustained maximal inspiration, chest physiotherapy, dan latihan batuk efektif.

\section{ABSTRACT}

COPD is a common disease that can be prevented and treated, characterized by persistent respiratory symptoms and limited air flow caused by the airways and / or alveolar abnormalities which are usually caused by significant exposure to harmful particles or gases that cause various disorders including congestion breath, changes in breathing pattern, muscle spasm, and decreased thoracic expansion. To determine the implementation of physiotherapy in reducing shortness of breath, normalizing breathing patterns, relaxing muscle, and increasing thoracic expansion with infra red, sustained maximal inspiration, chest physiotherapy, and effective cough exercise. After therapy for three times, the results of the assessmet of the degree of shortness breath T0: 6 to T3: 4, decreased pain in tenderness T0: 4 to T3: 2, motion pain T0: 2 to T3: 1, changes in breathing pattern T0: prolonged expiration became T3: prolonged expration, increased thoracic expansion on ICS $4 \mathrm{~T} 0: 1 \mathrm{~cm}$ to T3: $1.5 \mathrm{~cm}$, on processus xyphoideus T0: 1 $\mathrm{cm}$ to T3: $1.5 \mathrm{~cm}$ and increased activity T0: 70 to T3: 80 . Infra red, sustained maimal inspiration, chest physiotherapy, and effective cough exercise can overcome the problems that occur in cases of acute exacerbation of chronic obstructive pulmonary disease.

Keywords: Acute exacerbation of chronic obstructive pulmonary disease, infra red, sustained maimal inspiration, chest physiotherapy, and effective cough exercise

\section{PENDAHULUAN}

PPOK adalah penyakit umum yang dapat dicegah dan diobati, ditandai dengan gejala pernapasan persisten dan keterbatasan aliran udara yang disebabkan oleh saluran napas dan / atau kelainan alveolar yang biasanya disebabkan 
oleh paparan yang signifikan terhadap partikel atau gas berbahaya (Strategy et al., 2019).

Prevalensi PPOK di Indonesia yaitu 3,7\%. Provinsi dengan prevalensi tertinggi PPOK pada umur > 30 tahun berdasarkan gejala menurut hasil Riskesdas tahun 2013 adalah Provinsi Nusa Tenggara Timur $(10,0 \%)$, kemudian Sulawesi Tengah (8,0\%), dan Sulawesi Barat $(6,7 \%)$. Sedangkan prevalensi PPOK terendah menurut riset yang sama di tahun yang sama adalah Provinsi Lampung (1,4\%), kemudian Provinsi Riau, Jambi, dan Kepulauan Riau $(2,1 \%)$ (Kemenkes RI, 2013). Jumlah kasus PPOK di Provinsi Jawa Tengah dalam kurun waktu lima tahun semakin menurun, semula pada tahun 2012 terdapat 19.557 kasus menjadi 17.014 kasus pada tahun 2013 dan kasus tertinggi berada di Kota Salatiga (Dinkes Provinsi Jawa Tengah, 2013).

Karakteristik tanda dan gejala PPOK yang paling progresif yaitu sesak napas. Gejala lainnya berupa batuk, sputum, wheezing dan tightness pada dada maupun gejala tambahan seperti kelelahan saat berjalan terlalu jauh dan melakukan aktivitas yang berat salah satunya memasak untuk acara-acara besar, penurunan berat badan dan anoreksia pada PPOK yang sangat parah (Strategy et al., 2019).

\section{METODE PENELITIAN}

Metode penelitian dilakukan di Rumah Sakit Paru Ario Wirawan Salatiga dengan pasien bernama Ny. C berusia 79 tahun dengan diagnosa medis PPOK Eksaserbasi Akut. Pasien telah menjalani terapi sebanyak 3 kali dengan pemberian intervensi berupa infra red, chest physiotherapy dan latihan batuk efektif.

Pemberian modalitas infra red guna meningkatkan ekstensibilitas jaringan, meningkatkan jangkauan gerak sendi, mengurangi rasa sakit dan meningkatkan penyembuhan lesi jaringan lunak. Tujuan dari pemberian pursed lip breathing guna membuat saluran udara terbuka lebih lama dan mengurangi kerja pernapasan, memperpanjang pernafasan untuk memperlambat laju pernapasan, memperbaiki pola pernapasan dan meredakan sesak napas. Postural drainage digunakan untuk memindahkan sekresi dari berbagai segmen paru ke saluran udara yang lebih sentral. Pemberian tehnik cupping or clapping diharapkan dapat melepaskan sputum yang menempel pada dinding saluran napas. Latihan pernapasan Sustained Maximal Inspiration (SMI) bertujuan untuk meningkatkan kapasitas paru dan meningkatkan ekspansi thoraks. Dan pemberian latihan batuk efektif berguna untuk pembersihan jalan napas dari sputum.

\section{HASIL}

\section{Derajat Sesak Napas Dengan Borg Scale}

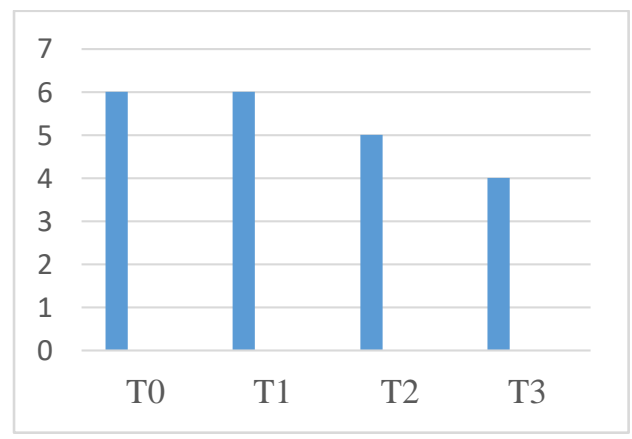

Gambar 1. Hasil Evaluasi Derajat Sesak Napas

Pemeriksaan derajat sesak napas yang dilakukan menggunakan borg scale belum terdapat pengurangan derajat sesak napas dari T0 ke T1 dengan nilai 6 yaitu sesak berat. Perubahan terjadi pada T2 dengan nilai 5 yaitu sesak berat, kemudian berkurang lagi pada T3 dengan hasil 4 yaitu kadang berat. 
Bintari R.P. \& Rahman F.

Fisiomu. 2020 Vol 1(2):35-41

DOI : 10.23917/fisiomu.v\%vi\%i.10439

Nyeri Spasme Pada Otot-Otot Pernapasan

\section{Dengan Numeric Rating Scale (NRS)}

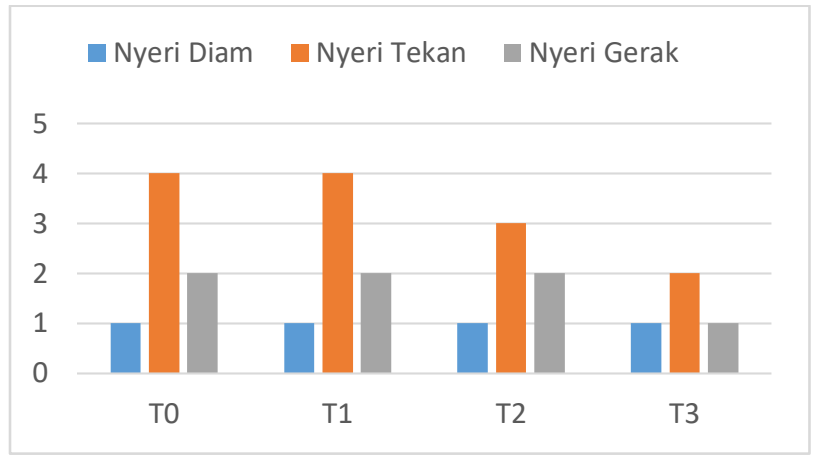

Gambar 2. Hasil Evaluasi Nyeri pada Spasme Otot-Otot Pernapasan
Penilaian nyeri spasme pada otot-otot pernapasan yang dilakukan menggunakan NRS mendapatkan hasil berupa:

a. Nyeri diam dari T0 dengan nilai 1 yaitu nyeri ringan menjadi $\mathrm{T} 2$ dengan nilai 1 yaitu nyeri ringan

b. Nyeri tekan dari T0 dengan nilai 4 yaitu nyeri sedang menjadi $\mathrm{T} 2$ dengan nilai 2 yaitu nyeri ringan

c. Nyeri gerak dari T0 dengan nilai 2 yaitu nyeri ringan menjadi $\mathrm{T} 2$ dengan nilai 1 yaitu nyeri ringan

\section{Ekspansi Thoraks Dengan Pita Ukur}

Tabel 1. Hasil Evaluasi Ekspansi Thoraks

\begin{tabular}{|c|c|c|c|c|c|c|c|}
\hline \multirow[b]{2}{*}{ Hasil } & \multirow[b]{2}{*}{ Keterangan } & \multicolumn{6}{|c|}{ Lokasi } \\
\hline & & $\begin{array}{l}\text { Axila } \\
(\mathrm{cm})\end{array}$ & $\begin{array}{c}\text { Selisih } \\
(\mathrm{cm})\end{array}$ & $\begin{array}{l}\text { ICS4 } \\
(\mathrm{cm})\end{array}$ & $\begin{array}{c}\text { Selisih } \\
(\mathrm{cm})\end{array}$ & $\begin{array}{c}\text { Proc. } \\
\text { xiphoideus } \\
\text { (cm) }\end{array}$ & $\begin{array}{c}\text { Selisih } \\
\text { (cm) }\end{array}$ \\
\hline \multirow{2}{*}{ T0 } & Inspirasi & 89 & \multirow{2}{*}{1} & 85 & \multirow{2}{*}{1} & 86 & \multirow{2}{*}{1} \\
\hline & Ekspirasi & 88 & & 84 & & 85 & \\
\hline \multirow{2}{*}{$\mathrm{T} 1$} & Inspirasi & 89 & \multirow{2}{*}{1} & 85 & \multirow{2}{*}{1} & 86 & \multirow{2}{*}{1} \\
\hline & Ekspirasi & 88 & & 84 & & 85 & \\
\hline \multirow{2}{*}{$\mathrm{T} 2$} & Inspirasi & 89 & \multirow{2}{*}{1} & 85 & \multirow{2}{*}{1} & 86 & \multirow{2}{*}{1} \\
\hline & Ekspirasi & 88 & & 84 & & 85 & \\
\hline \multirow{2}{*}{$\mathrm{T} 3$} & Inspirasi & 89 & & 85,5 & \multirow{2}{*}{1,5} & 87,5 & \multirow{2}{*}{1,5} \\
\hline & Ekspirasi & 88 & & 84 & & 86 & \\
\hline
\end{tabular}

Hasil evaluasi pemeriksaan ekspansi thoraks

a. Titik axila dari T0 dengan selisih $1 \mathrm{~cm}$ menunjukan adanya peningkatan yaitu : menjadi T3 dengan selisih $1 \mathrm{~cm}$ 
Bintari R.P. \& Rahman F.

Fisiomu. 2020 Vol 1(2):35-41

DOI : 10.23917/fisiomu.v\%vi\%i.10439

b. Titik ICS 4 dari T0 dengan selisih $1 \mathrm{~cm}$ menjadi T3 dengan selisih $1,5 \mathrm{~cm}$

c. Titik processus xyphoideus dari T0 dengan selisih $1 \mathrm{~cm}$ menjadi T3 dengan selisih 1,5 $\mathrm{cm}$

\section{Perubahan Pola Pernapasan Dengan Inspeksi}

Tabel 2. Hasil Evaluasi Perubahan Pola Pernapasan

\begin{tabular}{cc}
\hline Hasil & Keterangan \\
\hline T0 & Prolonged expiration \\
\hline
\end{tabular}

\begin{tabular}{cc}
\hline Hasil & Keterangan \\
\hline T1 & Prolonged expiration \\
\hline T2 & Prolonged expiration \\
\hline T3 & Prolonged expiration \\
\hline
\end{tabular}

Setelah dilakukan terapi sebanyak 3 kali dari T0 ke T3 belum terdapat perubahan pola pernapasan yaitu prolonged expiration.

\section{Penurunan Aktivitas Dan Kemampuan}

Fungsional Dengan Index Barthel

Tabel 3. Hasil Evaluasi Kemampuan Fungsional dengan Index Barthel

\begin{tabular}{|c|c|c|c|c|c|}
\hline Aktivitas & Penilaian & $\begin{array}{c}\text { Skor } \\
\text { T0 }\end{array}$ & $\begin{array}{c}\text { Skor } \\
\text { T1 }\end{array}$ & $\begin{array}{c}\text { Skor } \\
\text { T2 }\end{array}$ & $\begin{array}{c}\text { Skor } \\
\text { T3 }\end{array}$ \\
\hline Makan & $\begin{array}{l}0 \text { : Tidak dapat dilakukan } \\
\text { sendiri } \\
5: \text { Memerlukan bantuan dalam } \\
\text { beberapa hal } \\
10 \text { : Dapat melakukan sendiri }\end{array}$ & 10 & 10 & 10 & 10 \\
\hline Mandi & $\begin{array}{l}0 \text { : Tidak dapat dilakukan } \\
\text { sendiri } \\
5 \text { : Dapat dilakukan sendiri }\end{array}$ & 0 & 0 & 0 & 0 \\
\hline $\begin{array}{c}\text { Kebersihan } \\
\text { Diri }\end{array}$ & $\begin{array}{l}0 \text { : Membutuhkan bantuan } \\
5 \text { : Dapat melakukan sendiri } \\
\text { (sikat gigi, dll) }\end{array}$ & 5 & 5 & 5 & 5 \\
\hline Berpakaian & $\begin{array}{l}0: \text { Tidak dapat dilakukan } \\
\text { sendiri } \\
5: \text { Memerlukan bantuan } \\
\text { minimal } \\
10: \text { Dapat dilakukan sendiri }\end{array}$ & 5 & 5 & 5 & 5 \\
\hline Defekasi & $\begin{array}{l}0: \text { Inkontinensia alvi } \\
5: \text { Kadang terjadi inkontinensia } \\
10: \text { Tidak terjadi inkontinensia }\end{array}$ & 10 & 10 & 10 & 10 \\
\hline Miksi & $\begin{array}{l}0: \text { Inkontinensia urin atau } \\
\text { menggunakan kateter } \\
5: \text { Kadang terjadi inkontinensia } \\
10: \text { Tidak terjadi inkontinensia }\end{array}$ & 10 & 10 & 10 & 10 \\
\hline $\begin{array}{l}\text { Penggunaan } \\
\text { Toilet }\end{array}$ & $\begin{array}{l}0: \text { Tidak dapat melakukan } \\
\text { sendiri } \\
5: \text { Memerlukan bantuan } \\
10: \text { Mandiri }\end{array}$ & 5 & 5 & 5 & 5 \\
\hline
\end{tabular}


Bintari R.P. \& Rahman F.

Fisiomu. 2020 Vol 1(2):35-41

DOI : 10.23917/fisiomu.v\%vi\%i.10439

\begin{tabular}{|c|c|c|c|c|c|}
\hline Aktivitas & Penilaian & $\begin{array}{c}\text { Skor } \\
\text { T0 }\end{array}$ & $\begin{array}{c}\text { Skor } \\
\mathrm{T} 1\end{array}$ & $\begin{array}{c}\text { Skor } \\
\text { T2 }\end{array}$ & $\begin{array}{c}\text { Skor } \\
\text { T3 } \\
\end{array}$ \\
\hline Transfer & $\begin{array}{l}\text { (Dari tempat tidur ke kursi dan } \\
\text { kembali ke tempat tidur) } \\
0: \text { Tidak dapat melakukan, tidak } \\
\text { ada ke-seimbangan duduk } \\
5: \text { Perlu bantuan beberapa } \\
\text { orang, dapat duduk } \\
10 \text { : Perlu bantuan minimal } \\
15 \text { : Dapat melakukan sendiri }\end{array}$ & 10 & 10 & 10 & 15 \\
\hline Mobilitas & $\begin{array}{l}0: \text { Immobilisasi } \\
5: \text { Memerlukan kursi roda } \\
10: \text { Berjalan dengan bantuan } \\
15: \text { Mandiri/pakai tongkat }\end{array}$ & 10 & 10 & 10 & 15 \\
\hline $\begin{array}{l}\text { Naik Turun } \\
\text { Tangga }\end{array}$ & $\begin{array}{l}0 \text { : Tidak dapat melakukan } \\
5: \text { Perlu bantuan } \\
10: \text { Mandiri }\end{array}$ & 5 & 5 & 5 & 5 \\
\hline Total & & 70 & 70 & 70 & 80 \\
\hline
\end{tabular}

Penilaian yang dilakukan dari T0 dengan nilai 70 yaitu ketergantungan moderat menjadi T3 dengan nilai 80 yaitu ketergantungan moderat. Aktivitas dan kemampuan funsional pasien yang masih tergantung antara lain mandi, berpakaian, penggunaan toilet, transfer, mobilitas dan naik turun tangga. Adanya peningkatan aktivitas dan kemampuan fungsional pada terapi ke-3 yaitu terdapat pada penilaian transfer dan mobilitas dari T2 dengan nilai 10 menjadi T3 dengan nilai 15 .

\section{PEMBAHASAN}

Pasien atas nama Ny. C umur 79 tahun berjenis kelamin perempuan dengan diagnosa medis PPOK Eksaserbasi Akut telah diberikan penatalaksanaan fisioterapi sebanyak 3 kali terapi dengan menggunakan modalitas infra red, chest physiotherapy (breathing exercise, postural drainage, sustained maximum inspiration dan cupping) dan latihan batuk efektif, serta latihan aktivitas dan kemampuan fungsional untuk mengatasi problematika fisioterapi seperti sesak napas, sputum, nyeri pada spasme otot-otot pernapasan, perubahan pola pernapasan, penurunan ekspansi thoraks, dan penurunan aktivitas dan kemampuan fungsional. Beberapa intervensi yang telah diberikan memperoleh hasil yang baik dan perubahan yang cukup signifikan diantaranya terdapat pengurangan pada derajat sesak, adanya peningkatan ekspansi thoraks, rileksasi otot dan berkurangnya nyeri tekan pada otot bantu pernapasan. Akan tetapi belum terdapat perubahan pola pernapasan. Hal ini disebabkan karena adanya resistensi pada saluran pernapasan pada T1 sampai dengan T3 yaitu sputum pada paru-paru dextra lobus apex, medial dan basal maupun paru-paru sinistra lobus apex dan basal. Kondisi ini mempengaruhi aliran udara di dalam paru-paru dan pola pernapasan prolonged expiration.

\section{PENUTUP}

\section{Kesimpulan}

Penatalaksanaan chest physiotherapy dan latihan batuk efektif dapat mengurangi derajat sesak napas. Penatalaksanaan infra red, sustained maximal inspiration, chest physiotherapy dan latihan batuk efektif belum dapat memperbaiki pola pernapasan.Penatalaksanaan infra red, sustained maximal inspiration, chest 
Bintari R.P. \& Rahman F.

Fisiomu. 2020 Vol 1(2):35-41

DOI : 10.23917/fisiomu.v\%vi\%i.10439

physiotherapy dan latihan batuk efektif dapat meningkatan ekspansi thoraks.Penatalaksanaan infra red dan chest physiotherapy dapat rileksasi otot dan mengurangi nyeri tekan pada otot-otot pernapasan.

\section{Saran}

Penulis memberikan saran dengan harapan dapat memberi manfaat kepada pasien. Saran yang diberikan yaitu melakukan breathing exercise secara rutin di rumah, berjemur di bawah sinar matahari setiap pagi hari dan mengurangi aktivitas yang dapat menimbulkan sesak.

Saran yang dapat diberikan penulis kepada keluarga adalah memberikan dukungan moral, mengingatkan kembali pasien untuk berlatih terapi di rumah dan aktivitas yang berat sehingga dapat menimbulkan sesak napas.

\section{DAFTAR PUSTAKA}

Cross, J. L., Elender, F., Barton, G., Clark, A., Shepstone, L., Blyth, A., ... Harvey, I.
(2012). Evaluation of the effectiveness of manual chest physiotherapy techniques on quality of life at six months post exacerbation of COPD ( MATREX ): a randomised controlled equivalence trial. ???, 12(1), 1. https://doi.org/10.1186/14712466-12-33

Kesehatan, K., \& Indonesia, R. (2013). PROFIL KESEHATAN INDONESIA TAHUN 2013 (M. E. drg. Vensya Sitohang, M. K. Dr. drh. Didik Budijanto, M. Boga Hardhana, S.Si, \& M. K. drg. Titi Aryati Soenardi, eds.). Jakarta: Kementerian Kesehatan Republik Indonesia.

Press, D. (2014). Effect of repeated Waon therapy on exercise tolerance and pulmonary function in patients with chronic obstructive pulmonary disease: a pilot controlled clinical trial. 9-15.

Profil kesehatan provinsi jawa tengah tahun 2013. (2013).

Strategy, G., The, F. O. R., Of, P., Obstructive, C., \& Disease, P. (2019). Global Initiative for Chronic Obstructive Lung Disease. 